S97 INFLAMMATORY CYTOKINES ARE ELEVATED IN PATIENTS WITH OPERABLE CHRONIC THROMBOEMBOLIC PULMONARY HYPERTENSION AND PREDICT OUTCOME POST-ENDARTERECTOMY

doi:10.1136/thx.2010.150938.48

${ }^{1} \mathrm{E}$ Soon, ${ }^{2} \mathrm{~A}$ M Holmes, ${ }^{2} \mathrm{~L}$ Barker, ${ }^{3} \mathrm{C}$ Treacy, ${ }^{3} \mathrm{~J}$ Suntharalingham, ${ }^{3} \mathrm{M}$ Toshner, ${ }^{2} \mathrm{P}$ Nicklin, ${ }^{2} \mathrm{C}$ Walker, ${ }^{2} \mathrm{D}$ Budd, ${ }^{3} \mathrm{D}$ Jenkins, ${ }^{3} \mathrm{~K} \mathrm{~K}$ Sheares, ${ }^{3} \mathrm{~J}$ Pepke-Zaba, ${ }^{1} \mathrm{~N}$ W Morrell. ${ }^{1}$ University of Cambridge, Cambridge, UK; ${ }^{2}$ Novartis Horsham Research Centre, West Sussex, UK; ${ }^{3}$ Papworth Hospital NHS Trust, Cambridge, UK

Rationale Elevated levels of inflammatory cytokines have been reported in patients with idiopathic pulmonary arterial hypertension. The role of inflammation in chronic thromboembolic pulmonary hypertension (CTEPH) is largely unknown. We sought to establish the levels of circulating cytokines in patients with operable CTEPH and to determine if levels fall after pulmonary endarterectomy (PEA), a potentially curative therapy.

Methods Forty-four patients with severe CTEPH suitable for PEA were recruited prospectively. Patients were assessed pre- and 3 months post-PEA with right heart catheterisation, 6 min walk tests and determination of serum levels of interleukins (IL)- $1 b$, $2,4,5,6,8,10,12 \mathrm{p} 70$ and 13; TNF- $\alpha$ and IFN $\gamma$. Patients deemed at risk for residual CTEPH post-PEA were re-assessed invasively at a year post-PEA. Twenty-one healthy volunteers served as controls

Results CTEPH patients prior to PEA exhibited significantly raised levels of IL-1b, IL-2, IL-4, IL-8 and IL-10 compared to healthy controls. After PEA, IL-2 levels fell from $1.64(0.83-3.34)$ to 1.17 $(0.54-1.75) \mathrm{pg} / \mathrm{ml} \quad(\mathrm{p}=0.049)$, while IL-8 fell from 24.46 $(13.11-38.25)$ to $17.44(10.97-23.14) \mathrm{pg} / \mathrm{ml}(\mathrm{p}=0.017)$. IL- $1 \mathrm{~b}$ and IL-4 remained elevated compared to controls. Pre-PEA levels of IL-6 and IL- 8 were predictive of normalisation of PA pressures after PEA. Patients with a pre-PEA IL-6 level of $<7 \mathrm{pg} / \mathrm{ml}$ had a $62 \%$ cumulative probability of having a mean PAP of $<25 \mathrm{~mm} \mathrm{Hg} 1$ year after surgery, while patients with a pre-PEA IL-6 level of $\geq 7 \mathrm{pg} / \mathrm{ml}$ had a cumulative probability of $21 \%(p=0.01)$. A pre-PEA IL- 6 level of $\geq 7 \mathrm{pg} / \mathrm{ml}$ had a specificity of $80 \%$ and a sensitivity of $59 \%$ for identifying a patient at risk of having residual $\mathrm{PH}$ post-PEA, with a RR of 1.7 (95\% CI 1.1 to 2.6). A pre-PEA IL-8 level of $\geq 30 \mathrm{pg} / \mathrm{ml}$ had a specificity of $67 \%$ and a sensitivity of $64 \%$ for identifying a patient at risk of having residual $\mathrm{PH}$ post-PEA, with a RR of 1.7 (95\% CI 1.0 to 3.0 ).

Conclusions CTEPH patients exhibit raised levels of cytokines, suggesting an inflammatory component to disease pathogenesis. Certain cytokines, notably IL- 6 and IL-8, may be useful biomarkers to identify patients at risk for developing residual pulmonary hypertension.

\section{S98 VENTILATORY EFFICIENCY IN PULMONARY ARTERIAL HYPERTENSION AND CHRONIC THROMBOEMBOLIC PULMONARY HYPERTENSION: PHYSIOLOGICAL DIFFERENCES AND IMPLICATIONS FOR DISEASE-SPECIFIC END-POINTS}

doi:10.1136/thx.2010.150938.49

${ }^{1} \mathrm{Z}$ Zhai, ${ }^{1} \mathrm{~K}$ Murphy, ${ }^{2} \mathrm{H}$ Tighe, ${ }^{3} \mathrm{C}$ Wang, ${ }^{1} \mathrm{M}$ Wilkins, ${ }^{1} \mathrm{~S}$ Gibbs, ${ }^{1} \mathrm{~L}$ S Howard. ${ }^{1}$ Imperial College London, London, UK; ${ }^{2}$ Hammersmith Hospital, London, UK; ${ }^{3}$ Capital Medical University, Beijing, China

Background Measures of ventilatory efficiency during cardiopulmonary exercise testing (CPX), such as the $\mathrm{V}_{\mathrm{E}} / \mathrm{VCO}_{2}$ slope and venti-
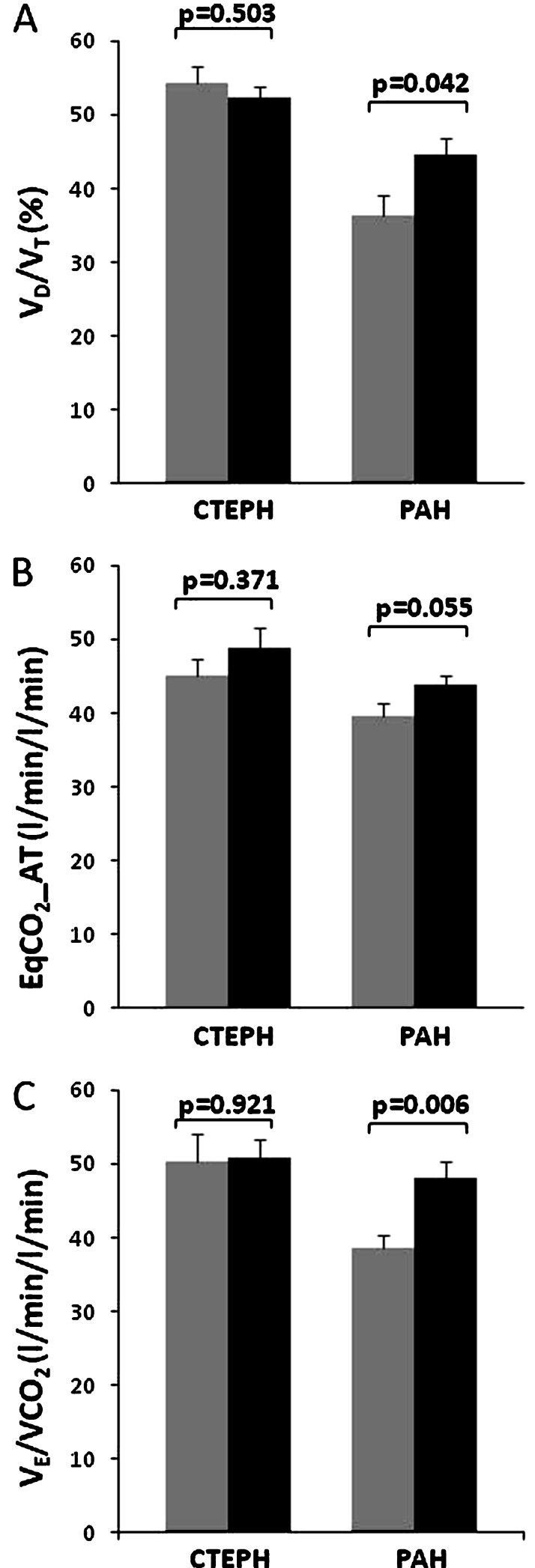

WHO FC I/II

WHO FC III/IV

Abstract S98 Figure 1 
latory equivalent for $\mathrm{CO}_{2}$ at anaerobic threshold $\left(\mathrm{EqCO}_{2} \mathrm{AT}\right)$, are increasingly being used as prognostic markers in heart failure and pulmonary arterial hypertension (PAH). Little is known about whether these measures can be applied to all forms of $\mathrm{PH}$, in particular chronic thromboembolic pulmonary hypertension (CTEPH), where thrombotic vascular occlusion may an impact on gas exchange through increased dead space fraction.

Methods and results 127 patients, 77 with CTEPH and 50 with PAH, underwent incremental CPX. Ventilatory dead space fraction $\left(V_{D} /\right.$ $\mathrm{V}_{\mathrm{T}}$ ) measured at peak exercise with arterial blood gas analysis was higher in CTEPH than PAH (52.9 vs 41.8, $\mathrm{p}<0.001$ ). The $\mathrm{V}_{\mathrm{E}} / \mathrm{VCO}_{2}$ slope was higher in CTEPH patients than in PAH patients (50.7 vs $44.4, \mathrm{p}=0.024)$ and was mirrored by similar changes in $\mathrm{EqCO}_{2} \mathrm{AT}$ (47.7 vs $42.0 \mathrm{p}=0.008$ ). Multivariate analysis demonstrated disease subtype to be a powerful independent predictor of $\mathrm{V}_{\mathrm{D}} / \mathrm{V}_{\mathrm{T}}$ $(\mathrm{p}<0.001), \mathrm{V}_{\mathrm{E}} / \mathrm{VCO}_{2}$ slope $(\mathrm{p}=0.003)$ and $\mathrm{EqCO}_{2} \mathrm{AT}(\mathrm{p}<0.001)$. These three measures could distinguish between WHO functional classes I/II and III/IV in PAH, but not CTEPH (Abstract S98 Figure 1). As a result of increased ventilatory inefficiency in CTEPH, breathing reserve was lower at peak exercise compared with $\mathrm{PAH}$ (29.0 vs $38.8, \mathrm{p}=0.003$ ) despite similar peak $\mathrm{VO}_{2}$ and heart rate reserves.

Conclusion Significant differences in gas exchange exist between CTEPH and PAH, possibly due to differences in $V_{D} / V_{T}$ as a result of vascular occlusion due to thromboembolic disease. These findings increase our understanding of the mechanisms of exercise limitation in subtypes of pulmonary hypertension, with increased dependence on gas exchange and ventilatory capacity in CTEPH. Furthermore these differences in gas exchange dissociate measures of ventilatory efficiency from disease severity in CTEPH. Caution should be applied in using common prognostic end-points from CPX in all forms of pulmonary hypertension.

\section{S99 MULTIPLE REGRESSION ANALYSES IN A COHORT OF HEREDITARY HAEMORRHAGIC TELANGIECTASIA PATIENTS SUGGEST A NOVEL ROLE FOR IRON IN THROMBOSIS}

doi:10.1136/thx.2010.150938.50

\footnotetext{
${ }^{1} \mathrm{~J}$ A Livesey, ${ }^{2} \mathrm{~J}$ E Jackson, ${ }^{1} \mathrm{C}$ L Shovlin. ${ }^{1} \mathrm{NHLI}$, Imperial College London, London, UK; ${ }^{2}$ Department of Imaging Imperial College Healthcare Trust, London, UK
}

Introduction/objectives Pulmonary emboli (PE) secondary to deep venous thromboses (DVT) are the immediate cause of $10 \%$ of hospital deaths. Elevated basal plasma coagulation factor (F) VIII levels, now known to be synthesised by the pulmonary endothelium, ${ }^{1}$ are the strongest predictor of recurrent PE/DVT, and also associated with elevated pulmonary artery pressure (PAP). The reasons for these associations are unknown. The study objectives were to determine whether novel patient-specific factors were associated with FVIII levels; PE/DVT; and/or PAP.

Methods Previous studies from our group have presented data on the 1999-2005 hereditary haemorrhagic telangiectasia (HHT) cohort of patients. In the current study, a replicate data series was generated from individuals seen between 2006 and 2010, and analysed independently to the first. Basal plasma FVIII measurements taken at least 4 months from any thrombotic event/intercurrent illness; and 32 patient-specific variables from 221 individuals, including cathetermeasured PAP and verified DVT/PE, were entered into an Excel chart. Following verification, data were analysed using STATA v11c (Statacorp LP) software. Univariate analyses identified potentially associated variables, which were analysed using stepwise multiple regression analyses, to generate best-fit models.

Results For FVIII, the most significant independent variables were identified as fibrinogen, age, and iron replacement therapy (IRT) (model: 4df; $\mathrm{p}<0.0001 ; \mathrm{r}^{2}$ 0.2014). Fibrinogen showed the most significant association with FVIII (OR 0.193, $\mathrm{p}<0.001$ ). FVIII showed further associations with age (OR 0.006, $\mathrm{p}=0.028$ ) and IRT (OR 0.162; $\mathrm{p}=0.075$ ). PE/DVT was associated with IRT (OR 1.416, $\mathrm{p}=0.028)$. Mean PAP was associated with age (OR 0.079, $\mathrm{p}=0.007$ ) and FVIII (OR 1.449, $\mathrm{p}=0.009$ ). Iron deficiency did not emerge as significant in any model. SIREs software predicted specific iron response elements (IREs) in FVIII mRNA splice-variants, including one in the $5^{\prime}$ UTR of splice-variant $2{ }^{1}$

Conclusions This study suggests that basal plasma FVIII levels, and associated clinical endpoints of PE/DVT and PAP, may be influenced by iron replacement therapy, possibly by modulating expression of specific splice-variants of the F8 gene. This study therefore suggests that iron replacement may increase thrombotic risk, with significant potential clinical implications for millions of people who take iron tablets.

\section{REFERENCE}

1. Shovlin, et al. PLOS ONE 2010:5:e9154.

\section{S100 CHANGE IN DIASTOLIC PULMONARY ARTERY PRESSURE (3 MONTHS POST SURGERY COMPARED TO PRE-SURGERY VALUE) AS A LONG-TERM PROGNOSTIC PARAMETER IN PATIENTS TREATED WITH PULMONARY ENDARTERECTOMY FOR CHRONIC THROMBOEMBOLIC PULMONARY HYPERTENSION}

doi:10.1136/thx.2010.150946.1

G C Hagan, C Treacy, K Sheares, D P Jenkins, J PepkeZaba, A Kacprzak. Papworth Hospital, PapworthEverard, UK

Introduction The definitive treatment for chronic thromboembolic pulmonary hypertension is pulmonary endarterectomy (PEA). Some patients are left with residual pulmonary hypertension after the surgery. We analysed post-PEA haemodynamics to assess their impact on long-term survival.

Methods We analysed systolic(sPAP), diastolic(dPAP) and mean (mPAP) pulmonary artery pressures, pulmonary vascular resistance (PVR) and changes $(\Delta)$ in these parameters measured at right heart catheterisation from pre-PEA to 3 months post PEA in 251 patients who underwent PEA in our centre in years 2000-2009. We assessed their usefulness as survival predictors using receiver operating characteristic (ROC) curves for 56 patients who completed at least 6 years follow-up. Eight of them died during this period, 48 survived. Subsequently, on the basis of ROC, we identified a cut-off value for change in diastolic pulmonary artery pressure $(\triangle \mathrm{dPAP})$, the parameter which had the biggest area under the curve (AUC). We divided the whole study population according to that value and performed Kaplan-Meier survival analysis.

Results AUCs were as follows: $\operatorname{sPAP}(0.57), \Delta \mathrm{sPAP}(0.7), \operatorname{dPAP}(0.72)$, $\Delta \mathrm{dPAP}(0.76), \operatorname{mPAP}(0.66), \Delta \mathrm{mPAP}(0.71), \operatorname{PVR}(0.65), \Delta \mathrm{PVR}(0.73)$ We chose $24.5 \mathrm{~mm} \mathrm{Hg}$ as a cut-off value for change in dPAP. It was characterised by $100 \%$ specificity and $41.9 \%$ sensitivity in predicting death within 6 years post-PEA. Kaplan-Meier survival analysis (with time zero taken at time of right heart catheter 3 months postPEA) for the whole group showed that patients with $\Delta$ dPAP $>24.5$ $\mathrm{mm} \mathrm{Hg}$ had significantly better survival rates in comparison to patients with $\Delta \mathrm{dPAP}<24.5 \mathrm{~mm} \mathrm{Hg}(\mathrm{p}=0.03)$ - Abstract S100 Figure 1. 13 of 59 patients with $\Delta$ dPAP $>24.5 \mathrm{~mm} \mathrm{Hg}$ still had pulmonary hypertension 3 months post-PEA. The overall 5 -year survival of the whole group was $80.8 \%$.

Conclusions 3 months post-PEA dPAP and $\triangle$ dPAP from pre-PEA values appeared to be the best survival predictor. The advantage of utilising dPAP is that it is a directly measured value and less susceptible to error then derived PVR. 